Kempegowda et al., Afr J Tradit Complement Altern Med., (2018) 15 (1): 11-25

https://doi.org/10.21010/ajtcam.v15i1.2

\title{
INHIBITORY POTENCY OF WITHANIA SOMNIFERA EXTRACTS AGAINST DPP-4: AN IN VITRO EVALUATION
}

\section{Praveen Kumar Kempegowda ${ }^{1}$, Farhan Zameer $^{2 * *}$, Chethan Kumar Narasimashetty ${ }^{3}$, Shiva Prasad Kollur ${ }^{4}$, Satish Kumar Murari ${ }^{5,6^{*}}$}

${ }^{1}$ Department of Biochemistry, Bharathiar University, Coimbatore - 641 046, Tamilnadu, India. ${ }^{2}$ Department of Biochemistry, School of Basic and Applied Sciences, Dayananda Sagar University, Shavige Malleshwara Hills, Kumaraswamy Layout, Bangalore - 560078 Karnataka, India. ${ }^{3}$ Sanjeevini Clinical Center, H.D. Kote Road, Mysore - 570 008, Karnataka, India. ${ }^{4}$ Laboratory of Synthetic and Materials Chemistry, Manipal Centre for Natural Sciences, Manipal University, Udupi - 576 104, Karnataka, India. ${ }^{5}$ Department of Chemistry, P.E.S. College of Engineering, Mandya - 571 401, Karnataka, India. ${ }^{6}$ PET Research Foundation, University of Mysore, Mandya - 571 401, Karnataka, India.

*Corresponding Author E-mail: msatish.1952@gmail.com

**Co-Corresponding Author E-mail: farhanzameeruom@gmail.com

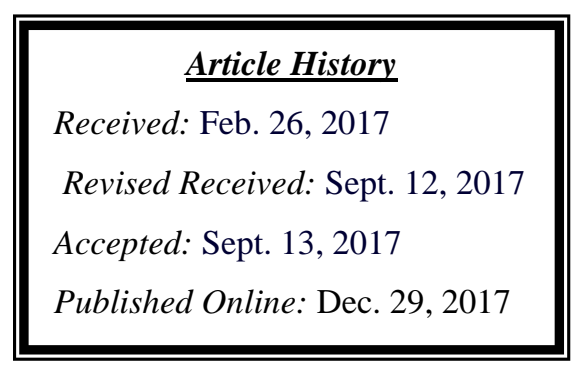

Abstract

Background: Pharmacologic treatments for type 2 diabetes are based upon increasing insulin availability and improving sensitivity to insulin. Nowadays, glucagon like peptide-1 (GLP-1) based therapies aims at glucose control through DPP-4 inhibitors. DPP-4 is a transmembrane glycoprotein belongs to prolyl oligopeptidase family, with the specificity of removing $\mathrm{X}$-Pro or X-Ala dipeptides from the N-terminus of polypeptides. GLP-1 effect by stimulating glucose-dependent insulin release from the pancreatic islets, inhibit inappropriate post-meal glucagon release and slow gastric emptying promoting leaky gut. The current study investigated DPP-4 inhibitory activity of catechin, isolated from Withania somnifera (WS), for ethnopharmacological treatment of type 2 diabetes and aimed to increase availability of GLP-1and sensitivity to insulin.

Materials and Methods: Young and matured fresh roots, leaves, and fruits of WS plant extract were considered and were systematically evaluated for DPP-4 inhibitory activity using in vitro method, enzyme kinetics, phytochemical analysis, RPHPLC, LCMS and ${ }^{1} \mathrm{H}$ and ${ }^{13} \mathrm{C}$ NMR method and structure-activity relationship (SAR) studies.

Results: In this study, methanol (100\% and $80 \%)$ extracts of WS matured root exhibited maximum DPP-4 inhibitory activity when compared to other extracts. The maximum DPP-4 inhibitory activity was found in $100 \%$ methanol extract of matured root. Phytobioactive was purified by RP-HPLC. The compound purified was found to be flavonoid and was characterized (LCMS, ${ }^{1} \mathrm{H}$ and ${ }^{13} \mathrm{C}$ NMR studies), identified as catechin. Auxiliary, molecular docking was performed using Ligand Fit method using PatchDock package. The study revealed the binding affinity of catechin with DPP-4 to be -6.601 $\mathrm{kcal} / \mathrm{mol}$ with 13 hydrogen interactions with the receptor and was very similar to the standard potent blockers withaferin A and others (cuscohygrine, scopoletin, sitoindoside IV, tropine), further confirming its hyperglycemic potency.

Conclusion: The study reveals that, $100 \%$ methanol extract of WS matured roots contains the compound- catechin, which exhibits DPP-4 inhibitory activity resulting in increased level of bioactive GLP-1 and GIP. In this background, we concluded that the WS will be a better source for further development as new antidiabetic drugs.

Keywords: Gly-pro-p-nitroanilide (GPPN), Diprotin-A (Ile-Pro-Ile), Catechin, Withaferin-A, Diabetes and Molecular docking. 


\section{Introduction}

Withania somnifera (L.) Dunal is a small, erect, evergreen woody under shrub, which belongs to Solanaceae family, it is a xerophytic plant that grows up to $30-150 \mathrm{~cm}$ in height. This plant grows in all dry parts of subtropical India, such as Karnataka, Rajasthan, Punjab, Gujarat Madhya Pradesh and Uttar Pradesh. Globally, it is also found in Congo, South Africa, Egypt, Morocco, Jordan, Pakistan and Afghanistan (Uddin et al., 2012). The fleshy roots when dry are cylindrical, gradually tapering down with a brownish white surface. Leaves are simple, ovate, glabrous, $10 \mathrm{~cm}$ long, dense beneath and sparse above. Flowers inconspicuous, greenish or lubrid-yellow, in axillary, umbellate cymes; berries small, globose, orange-red when mature, enclosed in the persistent calyx; seed yellow, reniform (Mirjalili et al., 2009). The species' name somnifera means "sleep-bearing" in Latin, indicating that Ashvagandha was considered a sedative (Barnett et al., 2006). However, it has also been used for sexual vitality and as an adaptogen (Mishra et al., 2000). In the traditional system of Ayurvedic medicine, this plant is claimed to have potent aphrodisiac rejuvenative and useful in the treatment of antiinflammatory, antitumour, antistress, antidiabetic, antiageing, stimulant for neurotransmitter and life prolonging properties (Sharma et al., 2011). The dried powder of the roots, leaves and berries of Withania somnifera (WS) contains phytoactives such as an alkaloids, steroidal lactones, flavonoids, tannin, saponins, somniferin etc. At present, more than 12 alkaloids, 40 withanolides, and several sitoindosides have been isolated and reported from Withania somnifera plant (Kulkarni and Dhir, 2008; Tursunova et al., 1977; Matsuda et al., 2001). Withaferin-A is the most important alkaloid and Withanolide D, steroidal lactone isolated so far from the leaves of WS and high catechin concentration detected in Withania somnifera have been reported (Mirjalili et al., 2009; Tiwari et al., 2014; Alam et al., 2011).

Type 2 diabetes mellitus (T2DM) or non-insulin-dependent diabetes mellitus (NIDDM) is possibly the world's foremost metabolic disorder that results from defects in insulin secretion on one side and insulin resistance on the other side of the $\beta$-cell (Tripathy et al., 2010). Hyperglycemia is mainly observed in people with increased concentration of carbohydrates and fats in their body; assisted with low physical activities (Anwer et al., 2008). Recently, considerable interest has been generated by a novel class of antihyperglycemic agents that act at distinct levels of the incretin therapies. The incretin therapies focus on the increasing levels of the two incretin hormones, glucagon like peptide-1 (GLP-1) and glucose-dependent insulinotropic polypeptide (GIP). Incretin hormones increase insulin secretion and they are the key modulators of pancreatic islet hormone secretion and regulate glucose homeostasis (Pratley and Salsali, 2007). GLP-1, derived from the L-cells of the distal small intestine and large bowel, and GIP, derived from the K-cells of the proximal small intestine (Dhananjayan et al., 2013). GLP-1 has direct effects on the endocrine pancreas, heart, stomach and brain and indirect effects on the liver and muscle (Drucker, 2006). Dipeptidyl peptidase-4 (DPP-4) (EC 3.4.14.5) or Cluster of differentiation 26 (CD26) is a cell-surface protease belonging to the prolyloligopeptidase family, it was first reported in 1966 and is essential for the control of GLP-1 bioactivity and glucose balance. It is expressed on a specific set of Tlymphocytes, where it is up-regulated after activation and also expressed in a variety of tissues, primarily on endothelial and epithelial cells (Lambert and Yang, 2003). GLP-1 is a 30-amino acid polypeptide that promotes blood glucose homeostasis by stimulating insulin secretion from pancreatic $\beta$-cells in a glucose-dependent manner. DPP-4 cleaves GLP-1 at the N-terminal end to release a dipeptide, thereby converting active GLP-1 (7-36 amide) to inactive GLP-1 (19-36 amide). Hence DPP-4 has emerged as a validated and biotarget for type 2 diabetes mellitus. An inhibitor of DPP-4 is likely to lower blood sugar levels by increasing the level of active GLP-1 (Joseph et al., 2009). The DPP-4 inhibitors enhance the body's own ability to control blood glucose by increasing the active levels of incretin hormones in the body. Their mechanism of action is distinct from the existing class of oral glucose-lowering agents. They control elevated blood glucose by triggering pancreatic insulin secretion, suppressing pancreatic glucagon secretion, and signaling the liver to reduce glucose production (Deacon, 2011).

In recent years, in silico modeling has become an important tool for drug designing. Virtual screening and molecular docking studies are of high priority in drug discovery and development (Lakshmi Ranganatha et al., 2013). Most of the molecular docking algorithms assume the enzyme as rigid object which leads to inappropriate correlation of the docking scores. There is no single docking algorithm or scoring function that can correctly predict the binding affinities of ligand in molecular interaction. For these reasons, in the present study, a highly validated docking program such as Ligand Fit method in Patch Dock software package was used to investigate and identify the interaction of ligand molecule in the active region of the protein and to predict the binding affinity between the ligand and the receptor protein molecules using atomic contact energy (ACE) or glide values (Madhusudan et al., 2016).

The pharmacological DPP-4 inhibitors as therapy of T2DM to attain adequate glycemic control is firmly established and numerous inhibitors are in varying stages of clinical development (Brown and Evans, 2012). The current DPP-4 inhibitors available are saxagliptin, sitagliptin, alogliptin and vildagliptin. Validagliptin is licensed in Europe and Latin America in 2007, alogliptin is licensed only in Japan in 2010 (Deacon, 2011; Brown and Evans, 2012; Verspohl, 2009). At the same time so many studies investigated adverse effect of current DPP-4 inhibitors were causes nasopharyngitis, upper respiratory tract infection, urinary tract infection, serious allergic reactions, headache, anaphylaxis, angioedema, Nausea, diarrhea and abdominal pain and low blood sugar levels specially when taken in over dosage (Chakrabarti et al., 2011; Idris and Donnelly, 2007; Pathak et al., 2010).But herbal products doesn't cause any side effects, 
our products is herbal. In the present study, different solvent extract of WS were studied for DPP-4 inhibitory activity and followed by isolation and characterization of the active compound, catechin. This study is the first report on catechin exhibiting the strong inhibition of DPP-4, which strongly supports the possible potential for the incretin, based antidiabetic therapy.

\section{Materials and Methods Chemical reagents}

Gly-pro-p-nitroanilide [GPPN], Diprotin-A [Ile-Pro-Ile], Porcine kidney DPP-4, Tris-HCl buffer and solvents used for extraction and purification were purchased from Sigma-Aldrich. All other chemicals were of analytical grade.

\section{Plant materials}

Young and matured fresh roots, leaves and fruits of WS plant were collected from Kestur Koppal village of Krishna Raja Nagar Taluk in Mysore District, Karnataka State, India [co-ordinate $-12.46^{\circ} \mathrm{N} 76.39^{\circ} \mathrm{E}$ ] in the month of August and September 2013 to 2014. It was identified and authenticated by competent botanist Dr. Rajakumar H. Garampalli with voucher specimen number PK2013. The herbarium of the same was deposited in the Department of studies in Botany, University of Mysore, Mysore and Karnataka, India. All samples were processed as per the schema shown in Fig.1.

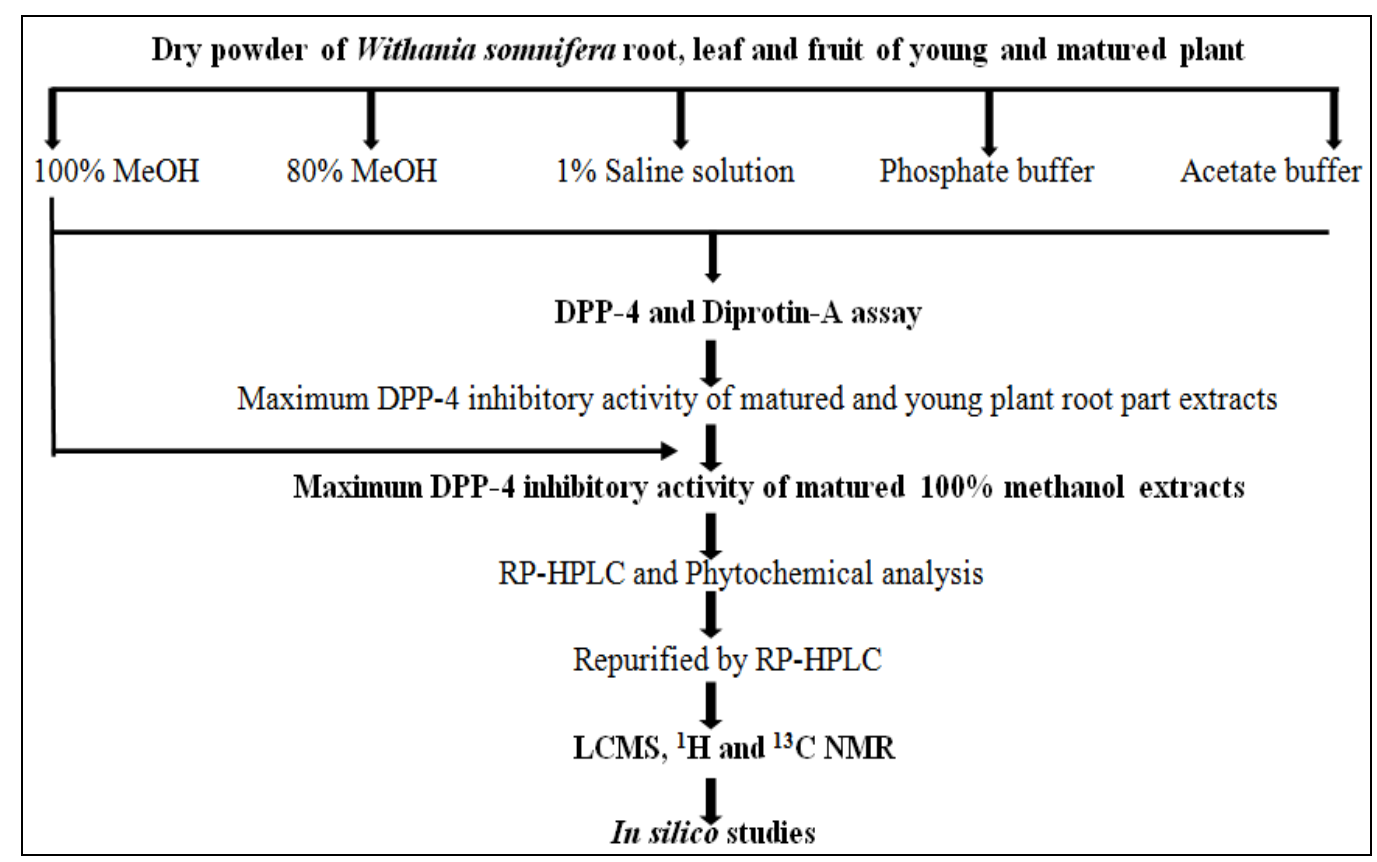

Figure 1: Schematics of the work flow.

\section{WS plant methanol extract}

The collected root, leaf and fruit parts of the plant was brought into the laboratory, cleaned, shade dried and then ground into fine powder. About $200 \mathrm{~g}$ of root, $70 \mathrm{~g}$ of leaf and $25 \mathrm{~g}$ of fruit dry powder of matured and young plant of WS was extracted with $80 \%$ and $100 \%$ methanol, at $70^{\circ} \mathrm{C}$ by continuous hot percolation using a Soxhlet apparatus. The extraction was continued for $24 \mathrm{hrs}$ and then extract were filtered and kept in oven at $40^{\circ} \mathrm{C}$ for 24 hrs to evaporate the solvents moisture. The concentrated extract was dissolved in minimal amount of water and washed three times with chloroform. The residual layer was extracted three thrice with ethyl acetate. All the extracts are finally pooled and concentrated using the rotator evaporator. The yield of $100 \%$ and $80 \%$ methanol extracts from matured and young root, leaf and fruit extract were collected then labelled specifically and kept separately in air tight containers in a deep freezer until the time of use for the screening of enzyme inhibitory activity and further studies (Rahman, 2013; Tomsone et al., 2012; Sinha, 2012). 


\section{WS plant Buffers and saline extract}

About $200 \mathrm{~g}$ of root, $70 \mathrm{~g}$ of leaf and $25 \mathrm{~g}$ dry powder of matured and young plant of WS was cold macerated with $1 \%$ saline solution, phosphate buffer $(0.2 \mathrm{M}, \mathrm{pH} 7.4)$ and acetate buffer $(0.2 \mathrm{M}, \mathrm{pH} 4.5)$ with intermittent shaking at 2 hrs intervals for $72 \mathrm{hrs}$. The filtrate obtained was concentrated using rotator evaporator. A highly non-polar solvent such as hexane was used to remove the chlorophyll and pigments out of the extract. The extract was then centrifuged with 10,000 $\mathrm{rpm}$ for about an hour and concentrated supernatant were transferred to a clean vial. The yield of $1 \%$ saline solution, phosphate buffer $(0.2 \mathrm{M}, \mathrm{pH} 7.4)$ and acetate buffer $(0.2 \mathrm{M}, \mathrm{pH} 4.5)$ extracts from matured and young root, leaf and fruit extract were collected then labelled specifically and kept separately in air tight containers in a deep freezer until the time of use for the screening of enzyme inhibitory activity and further studies (Rahman, 2013; Tomsone et al., 2012; Sinha, 2012).

\section{DPP-4 assay}

The in vitro inhibition of DPP-4 was assayed as described by Kojima et al. (1980) method. The substrate was cleaved by the enzyme serine aminopeptidase DPP-IV resulted the release of paranitroaniline (pNA), a yellow coloured product which was measured at $410 \mathrm{~nm}$. The varied concentration of plant extract $(5,25$ and $125 \mu \mathrm{g} / \mathrm{mL})$ and Diprotin-A as standard inhibitor in $1 \mathrm{~mL}$ of Tris- $\mathrm{HCl}$ buffer $(\mathrm{pH} 8.4)$ was pre-incubated with $50 \mu \mathrm{L}$ of DPP-4 $(0.05 \mathrm{U} / \mathrm{mL}$ ) enzyme for 30 min at $37^{\circ} \mathrm{C}$. After pre-incubation, $60 \mu \mathrm{L}$ of $10 \mathrm{mM}$ gly-pro-p-nitronilide was added and the final reaction mixture was made up to $1.5 \mathrm{~mL}$ using Tris- $\mathrm{HCl}$ buffer $(\mathrm{pH} 8.4)$ and then incubated at $37^{\circ} \mathrm{C}$ for $30 \mathrm{~min}$ and absorbance was finally read at $410 \mathrm{~nm}$. One unit of enzyme activity was defined as the amount of enzyme that catalyzes the release of $1 \mu \mathrm{mol}$ of p-nitroniline from the substrate/min under assay conditions (Baetta and Corsini, 2011; Kojima et al., 1980; Yogisha and Raveesha, 2010).

\section{Statistics}

Data were expressed as the mean \pm S.E.M. For statistical analysis of the data, percentage of inhibition was calculated using the following formula:

Percentage Inhibition $=\quad$ Absorbance of control - Absorbance of inhibitor $\times 100$

Absorbance of control

\section{Determination substrate Km value}

Determination of the Km value (Michaelis-Menten) for gly-pro-p-nitronilide ( 0.5 to $400 \mu \mathrm{M})$ as per the method of Liu et al., 2012. Before adding the substrate, $1 \mathrm{~mL}$ of Tris-HCl buffer $(\mathrm{pH} 8.4)$ was pre-incubated with $50 \mu \mathrm{L}$ of DPP-4 $(0.05 \mathrm{U} / \mathrm{mL})$ enzyme for $30 \mathrm{~min}$ at $37^{\circ} \mathrm{C}$. After incubation the reaction was initiated by addition of various concentration of substrate finally read at $410 \mathrm{~nm}$. The reaction mixture without enzyme was used as blank. The substrate concentration values was analyzed in GraphPhad prism nonlinear regression curve fit through the link of enzyme kinetics. From the Michaelis-Menten equation we determined the Km and Vmax of enzyme with different parameters.

Using equation for $\mathrm{Km}$ value calculation: $\mathbf{Y}=\mathbf{V} \mathbf{m a x}^{*} \mathbf{X} /(\mathbf{K} \mathbf{m}+\mathbf{X})$

Where 'X', 'Y', 'Vmax' and 'Km' are substrate concentration, intial velocity, maximum velocity, Michaelis-Menten constant respectively.

\section{Determination of Ki value}

Determination of the Ki value (Competitive inhibition) the concentrations of gly-pro-p-nitronilide varied from 0.5 to $800 \mu \mathrm{M}$ as per the method of Xiao et al., 2016. In the investigation was in the absence or presence of WS methanolic extracts at various concentrations $(0.1-125.0 \mu \mathrm{M} / \mathrm{mL})$. Dissolved in in Tris- $\mathrm{HCl}$ buffer $(\mathrm{pH} 8.4)$ and follow the methods of above DPP-4 assay with various concentration of substrate gly-pro-p-nitronilide from 0.5 to $800 \mu \mathrm{M}$ the reaction was initiated by addition of enzyme and the reaction measured at $410 \mathrm{~nm}$. The absorbance and various concentrations of substrate was analysed in GraphPhad prism nonlinear regreation curve fit through the link of enzyme kinetics and competitive inhibition using below equation to the determined Ki, Km and Vmax of enzyme with best fit values. 
Using equation for calculation of $\mathrm{Ki}$ value:

\section{$\mathrm{KmObs}=\mathrm{Km}(1+[\mathrm{I}] / \mathrm{Ki})$ and $\mathrm{Y}=\mathrm{Vmax} * \mathrm{X} /(\mathrm{KmObs}+\mathrm{X})$}

' $\mathrm{X}$ ', 'Y', 'Vmax', 'Km', 'Ki' and 'I' are substrate concentration, enzyme velocity, maximum velocity, Michaelis-Menten constant, inhibition constant and inhibition concentration respectively.

\section{Fractionation of extracts by HPLC}

Based on screening different parts of the WS extract for inhibition of DPP-4, 100\% methanolic root extract has shown the highest inhibition. Hence this extract was $(5 \mathrm{~mL})$ was injected into the HPLC C-18 column (SHIM-PACK, $2.2 \times 25 \mathrm{~cm}$, particle size $10 \mu \mathrm{m}$ and pore size $30 \mathrm{~nm}$ ), attached to a LC-8A, Shimadzu HPLC system (Shimadzu Asia Pacific Pvt. Ltd, Singapore), was done at $37^{\circ} \mathrm{C}$ using solvent A as triple distilled water with $0.1 \%$ tri-fluroaceticacid and solvent B as methanol with $0.1 \%$ tri-fluroacetic acid. Flow rate was maintained at $7 \mathrm{~mL} / \mathrm{min}$ and run time was $45 \mathrm{~min}$. The eluted sample observed at different wavelength and chromatogram was recorded (Khoddami et al., 2013; Rajasekar and Elango, 2011; Ghafoor et al., 2012; Dalavayi et al., 2006). The peak area of eluted samples was collected in different fraction and was used to determine DPP-4 inhibitor activity as per the Kojima et al., (1980) method.

\section{Phytochemical analysis}

The fractions from HPLC column were analyzed for phytochemicals by qualitatively for the identification of active compounds namely alkoloids, terpenoids, flavonoids, proteins, tannins and saponins by Drogendroff's test, Salkowski test, aluminum chloride test, Million's test, lead sub acetate Test and Frothin test respectively.

\section{Shinoda's test for flavonoids}

About $0.5 \mathrm{~mL}$ of each sample was dissolved in ethanol, warmed and then filtered. Three pieces of magnesium chips was then added to the filtrate followed by few drops of Conc. $\mathrm{HCl}$. A red to purple colouration indicates the presence of flavonoids was analysis as per the Usman et al., 2009; Trease and Evans 2002.

\section{Ferric chloride test for flavonoids}

About $0.5 \mathrm{~mL}$ of each sample was boiled with distilled water and then filtered. To $2 \mathrm{~mL}$ of the filtrate, few drops of $10 \%$ ferric chloride solution were then added. A violet coloration indicated the presence of a phenolic hydroxyl group was analysis as per the Usman et al., 2009; Trease and Evans 2002.

\section{RP-HPLC with standard flavonoids compound}

The HPLC fraction peak which confirmed positive results of flavonoid from phytochemical analysis and showed maximum inhibitory activity was used for further purification process by preparative HPLC followed by the above procedure and on the other hand, standard flavonoids compound (Gallic acid, Gentisic acid, Catechin, Caffeic acid, Epicatechin, p-Coumaric acid, Myricetin, Quercetin) were also injected, System was done at $30^{\circ} \mathrm{C}$ using solvent A as triple distilled water with $0.1 \%$ tri-fluroaceticacid and solvent $\mathrm{B}$ as methanol with $0.1 \%$ tri-fluroaceticacid, flow rate was maintained $7 \mathrm{~mL} / \mathrm{min}$ and run time was $45 \mathrm{~min}$. The eluted sample observed at different wavelength and chromatogram was recorded (Alam et al., 2011; Dalavayi et al., 2006). The peak area of the eluted samples collected in different fraction and used to determine DPP-4 inhibitor activity as per the Kojima et al., (1980) method.

\section{Mass spectrophotometer}

All electrospray ionization experiments were performed using a QSTAR XL hybrid mass spectrometer (AB/MDS Sciex) hyphenated with microscale capillary reversed-phase HPLC (Famous autosampler (LC Packings), Agilent 1100 HPLC pump (Agilent). The columns were packed in-house using Magic C-18 (5_m, $200 \AA$ A, Michrom BioResources) beads. The solvent compositions are as follows: by methanol with $0.1 \%$ tri-fluroaceticacid and water with $0.1 \%$ tri-fluroaceticacid. For the quantitation experiments a $5 \mathrm{~min}$ gradient was used with mass spectra being acquired every $0.15 \mathrm{sec}$. Data analysis and quantitation was done using the Analyst software package provided by Applied Biosystems/MDS Sciex. 


\section{${ }^{1} \mathrm{H}$ and ${ }^{13} \mathrm{C}$ NMR spectral measurements}

The ${ }^{1} \mathrm{H}$ and ${ }^{13} \mathrm{C}$ NMR spectra were recorded on a Bruker Avance $400 \mathrm{MHz}$ spectrometer (Bruker cop. Germany) using TMS as internal standard and $\mathrm{CDCl}_{3}$ as solvent at ambient temperature. The NMR characterization is helpful in predicting the molecular structure of an isolated compound. Usually, the compound whose molecular structure needs to be elucidated is taken $(\sim 5 \mathrm{mg})$ into a clean NMR tube and dissolved using deuterated solvent $\left(\mathrm{CDCl}_{3}\right.$, in this case) (Kumar et al., 2016).

\section{Molecular Docking \\ Structure-Activity Relationship (SAR) studies:}

Molecular docking was performed to establish the correlation between the WS isolated and characterized catechin molecule (Pub chem. CID - 73160) and the top five potent inhibitors namely Cuscohygrine (Pub chem. CID - 441070), Scopoletin (Pub chem. CID - 5280460), Sitoindoside IV (Pub chem. CID - 127197), Tropine (Pub chem. CID - 449293) and Withaferin A (Pub chem. CID - 265237) respectively with that of the target DPP-4 enzyme (Accession: PDB-1nu6). The crystal structure were built using CPH Models server 3.0. Energy computations were performed on the molecule using GROMOS96 implementation of Swiss-PDB Viewer. Electrostatic point charges on the molecules were calculated. The ligands were docked into the active site using the Molecular Docking software PatchDock with default parameters (Mashiach et al., 2010). PatchDock is an algorithm for calculating the docking modes of small molecules into proteinbinding sites based on their shape complementarity. In this we have used ChemScore, a scoring function that is derived from regression against receptor-ligand binding free energies. The structures of the ligands for the current study were constructed using Dundee PRODRG Server (Thomsen and Christensen, 2006) which optimizes the conformation of the side chains and minimizes the energy. The minimum energy conformers of ligands were interactively docked into close proximity with the enzyme active site pocket. The possibility of binding, precise location of binding sites and the mode of ligand binding was carried out using automated MolDock software, which is based on guided differential evolution and a force field-based screening function (SchuÈttelkopf and Van Aalten, 2004). Possible binding conformation and orientations were analyzed by clustering methods using the enzymatic model. The enzyme was visualized using sequence option. The binding site was computed within spacing such that the binding site was well sampled with a grid resolution of $0.3 \AA$. The ligand was docked into this grid using the Pymol Optimizer algorithm and its interactions monitored using detailed energy estimates. A maximum population of 100 and maximum interactions of 10,000 were used for each run and the five best poses were retained. The software was utilized to identify hydrogen bonds and hydrophobic interactions between residues at the active site and the ligand (Rakesh et al., 2016).

\section{Results}

Methanol [80\% and 100\%], $1 \%$ saline solution, $0.2 \mathrm{M}$ phosphate buffer ( $\mathrm{pH} 7.4)$ and $0.2 \mathrm{M}$ acetate buffer (pH 4.5) extracts of the root, leaves and fruit part of the young and matured plant of WS was studied for inhibition of DPP-4 activity. Preliminary level of screening was performed at a concentration of $25 \mu \mathrm{g} / \mathrm{mL}$ of each extract for DPP-4 inhibitoty activity, where WS root parts showed the maximum inhibition activity compared to leaves and fruit extracts as shown in Fig. 2A and Fig. 2B. Based on the results the above screening samples were narrowed down to root parts for further studies. Dose dependent studies $(5 \mu \mathrm{g} / \mathrm{mL}$ and $125 \mu \mathrm{g} / \mathrm{mL})$ of different concentration of young and matured root extracts were performed. Meanwhile, inhibitory activity for leaves and fruits extract were less significant than compared to the root extract. Henceforth, root extracts were subjected for further studies. The $100 \%$ and $80 \%$ methanolic extract of matured roots of WS shown $86.0 \pm 0.61 \%$ and $81.9 \pm 0.06 \%$ inhibition of DPP-4 respectively at $125 \mu \mathrm{g} / \mathrm{mL}$. The methanol extract macerated with $1 \%$ saline solution, phosphate buffer and acetate buffer showed $70.4 \pm 0.72 \%, \quad 80.3 \pm 0.29 \%$ and $71.2 \pm 1.19 \%$ of inhibition respectively at a concentration of $125 \mu \mathrm{g} / \mathrm{mL}$ in all the cases (Fig. 2B). Similar to the mature root extract, the $100 \%$ and $80 \%$ methanol, saline solution, phosphate and acetate buffer extract of young root inhibited the DPP-4 activity. The respective inhibition percentage is shown in the (Fig. 2A). The percentage of inhibition of DPP-4 by the matured root extract was found to be high compared to the young root extract; hence we proceeded with $100 \%$ methanolic extract of matured root for the purification and characterization of active compounds present in it. The $100 \%$ and $80 \%$ methanolic extracts of WS matured root were showed good inhibition activity with an $\mathrm{IC}_{50}$ value of $8.76 \mu \mathrm{g} / \mathrm{mL}$ and $21.03 \mu \mathrm{g} / \mathrm{mL}$ respectively. Diprotin-A served as the positive control, well knew inhibitor of DPP-4. Linear regression of standard inhibitor of diprotin- $\mathrm{A} \mathrm{IC}_{50}$ value was $4.1346 \mu \mathrm{g} / \mathrm{mL}$ and $\mathrm{p}$-value was 0.0109 with significance showed in fig. 3A. 


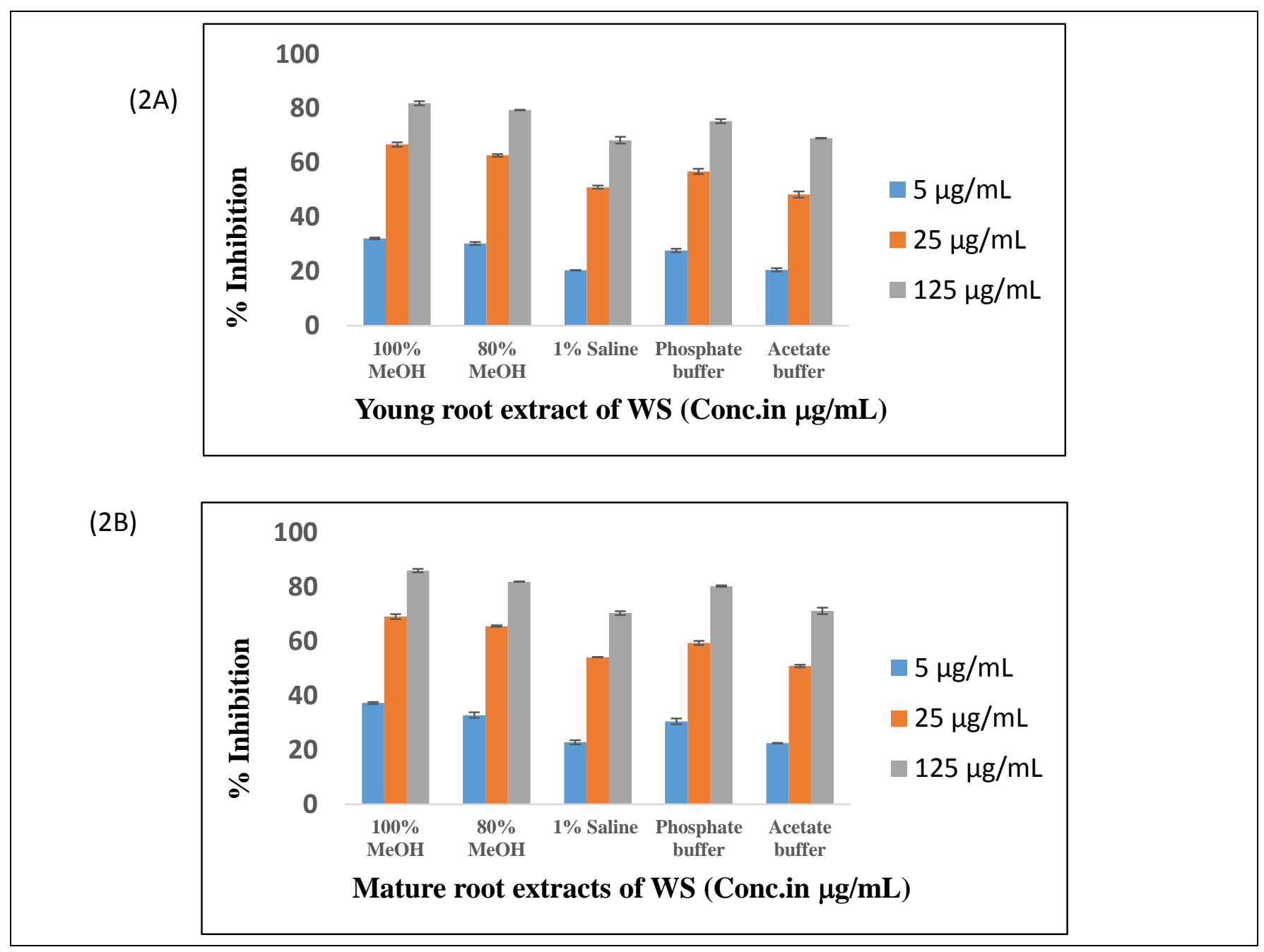

Figure 2: Dose dependent enzyme inhibitory activity of (A) young root and (B) mature root extracts of Withania somnifera.

The Km value determination was done in GraphPad prism software nonlinear regression curve fit, enzyme kinetics and Michaelis-Menten by varied the concentration of the substrate Gly-Pro-pNA ( $0.5 \mathrm{mM}$ to $400 \mathrm{mM})$ and DPP-4 enzyme activity graph showed in the fig.3B. Michaelis-Menten of substrate concentration results in various parameters It was found that "Best-fit values" the Km value was $97.70 \mu \mathrm{M}$ and Vmax value was $2.737 \mu \mathrm{M}$. "95\% Confidence Intervals" the Km value was 55.01 to $140.4 \mu \mathrm{M}$ and Vmax value was 2.288 to $3.186 \mu \mathrm{M}$ and "Goodness of Fit" the $\mathrm{R}^{2}$ is 0.9885 with 6 Degree of Freedom. The Ki value determined by GraphPad prism software through the competitive inhibition at 5, 25 and 125 $\mu \mathrm{M} / \mathrm{mL}$ of plant extracts, obtained graph in fig.3C and showed the results in Best-fit values parameters. It was found that Ki value was " 4.157e+016" $\mu \mathrm{M}, \mathrm{Km} \&$ Vmax values were $221.1 \mu \mathrm{M}$ and $2.352 \mu \mathrm{M}$ respectively. 


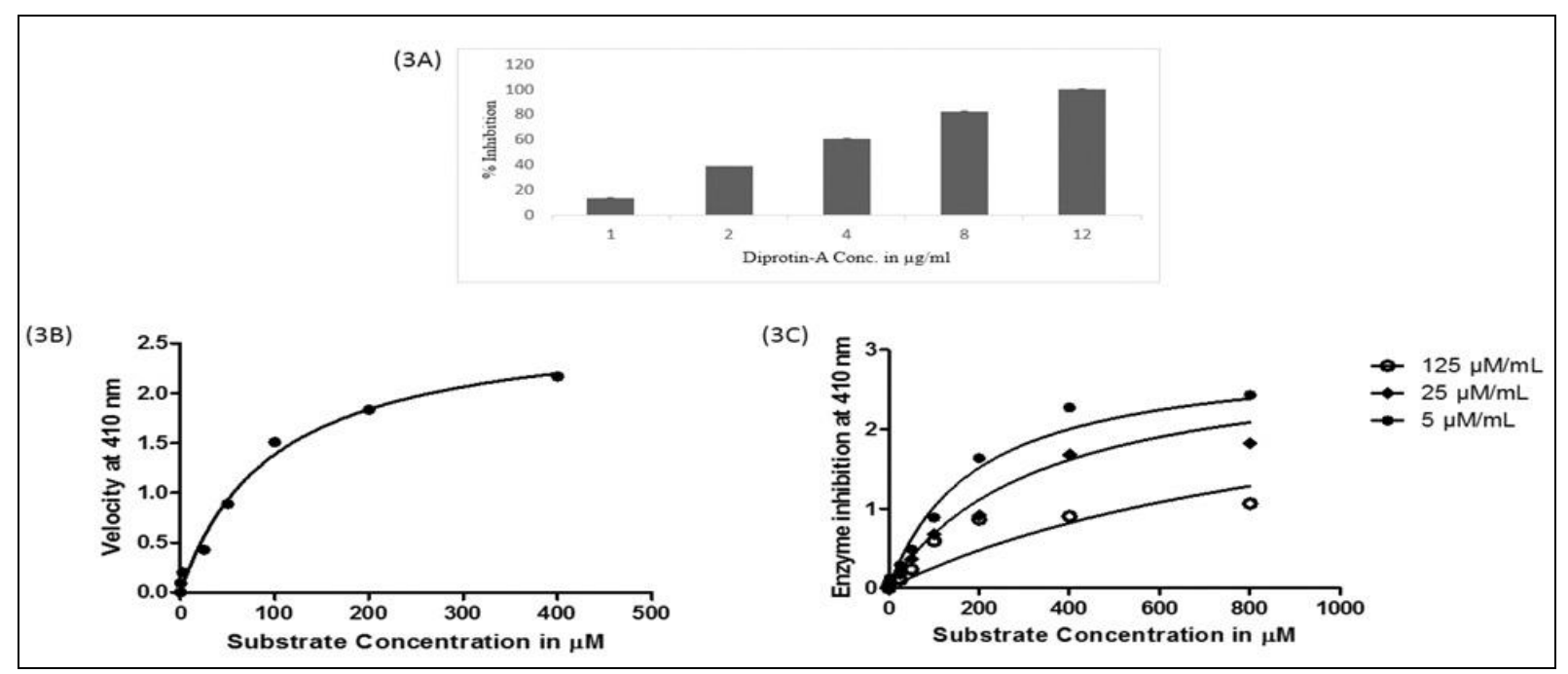

Figure 3: (A) Standard Diprotin-A (B) Km value of substrate concentration and (C) Ki value of inhibitory concentration. Further, 100\% methanol extract of matured root was subjected to preparative HPLC for the isolation of active principles.

As revealed in the HPLC chromatogram (Fig. 4A), the matured root extract was fractionated into many peaks and each peak were analyzed for DPP-4 inhibitory activity. Among all the peak fractions, the fractions which have retention time of 14 to 16 min exhibited DPP-4 inhibitory activity and hence these fractions were pooled and lyophilized until further use. The qualitative phytochemical analysis was carried out in the pooled samples obtained from HPLC chromatogram. Drogendroff's test, Salkowski test, ferric Chloride test, Million's test, Lead sub acetate test and Frothin test were carried for the presence of phytochemical constituents. The pooled fractions showed only positive result for Ferric chloride test and Shinoda's test suggesting the presence of flavonoids.

Further, purification and characterization was performed by HPLC followed by LCMS for the confirmation of flavanoids. The pooled sample from the HPLC chromatogram was further rechromatoghraphed by HPLC. There were many peaks in the re-chromatographed chromatogram (Fig. 4B) and the peak having the retention time 15.827 min was comparatively similar with the standard compound catechin, but other standard compounds like Gallic acid, Gentisic acid, Caffeic acid, Epicatechin, p-Coumaric acid, Myricetin, Quercetin were not matched to any other peaks. The same fraction was found to have maximum inhibitory activity than compared to other peaks and crude extracts. With all this bioanalytical background, the flavonoid compound was identified as catechin.

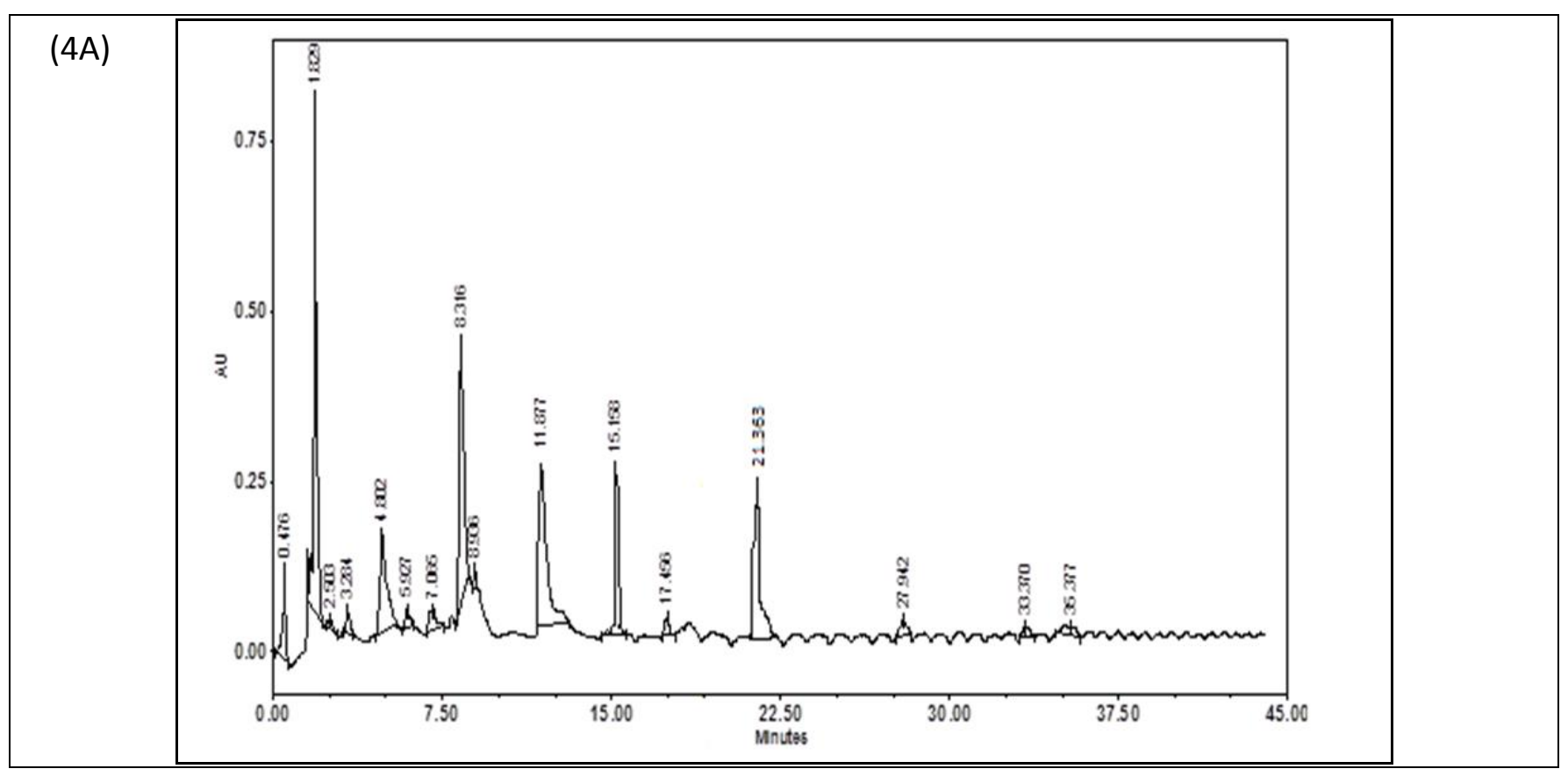




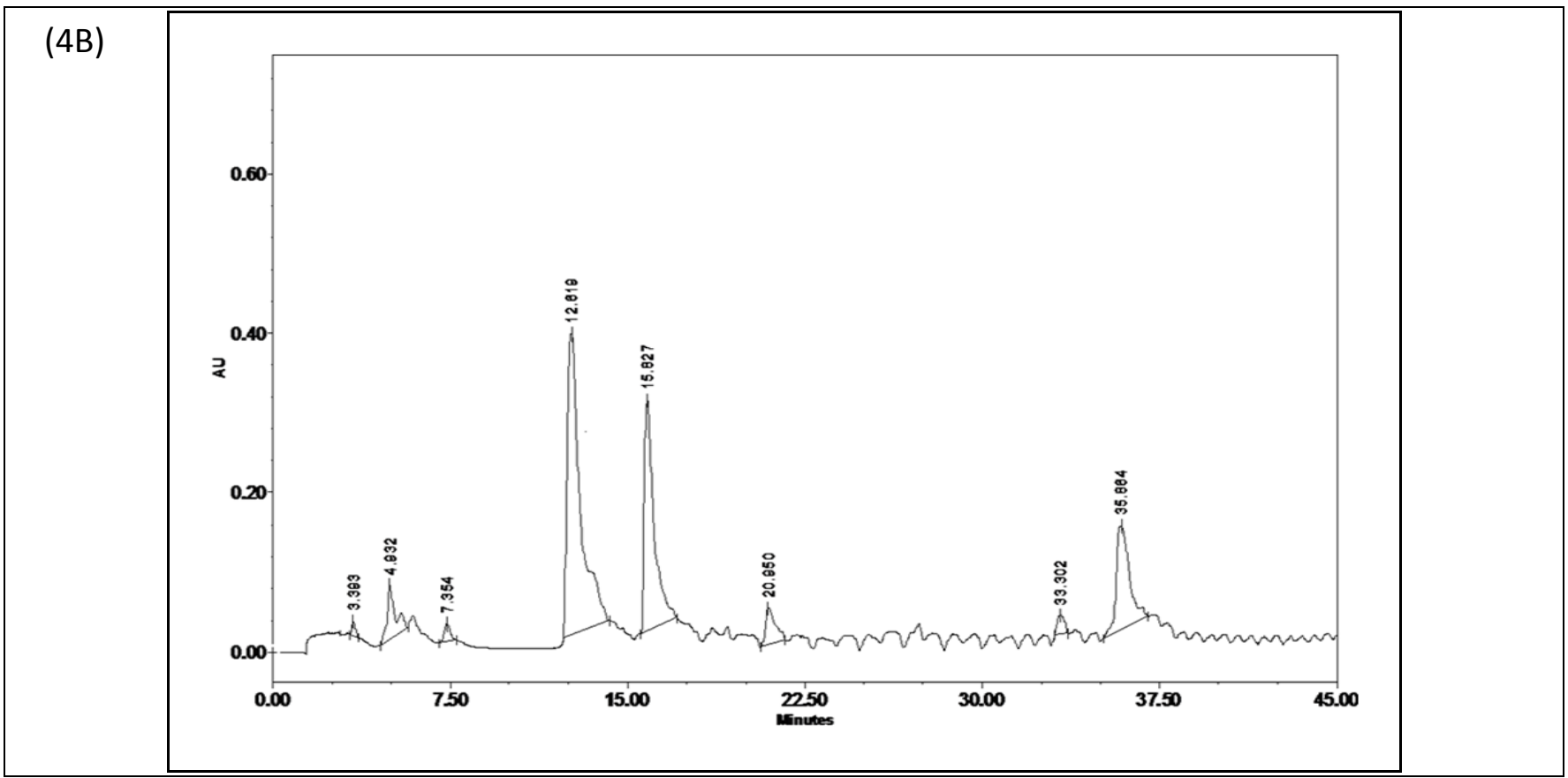

Figure 4: (A) Maximum DPP-4 inhibitor fraction was injected to C-18 column, (B) Repurification of the active fraction using RP-HPLC.

The spectrum was recorded in the ESI +ve mode on a QSTAR XL hybrid mass spectrometer and the calculated mass was found to be $288.87 \mathrm{Da}$ in Fig. 5A. and as the data of ${ }^{1} \mathrm{H}$ and ${ }^{13} \mathrm{C}$ NMR spectra shown in Fig. 5B and Fig. 5C, Yield: $14 \mathrm{mg}$ (Creamish yellow colour ); IR (KBr): 3400, 2600, 1618, 1520, 1470, 1380, 1280, 1240, 1150, 1120, 1080, $1020,820 \mathrm{~cm}^{-1} \mathrm{UV} \lambda_{\max } 277$ and $220 \mathrm{~nm} ;{ }^{1} \mathrm{H}-\mathrm{NMR}\left(400 \mathrm{MHz}, \mathrm{CDCl}_{3}\right) \delta 7.08(1 \mathrm{H}, \mathrm{d}, \mathrm{Ar}-\mathrm{H}, J=8 \mathrm{~Hz}), 6.93(1 \mathrm{H}, \mathrm{d}, \mathrm{Ar}-\mathrm{H}, J$ $=4 \mathrm{~Hz}), 6.79(1 \mathrm{H}, \mathrm{ddd}, \mathrm{Ar}-\mathrm{H}, J=4 \mathrm{~Hz}), 5.61-5.43(2 \mathrm{H}, \mathrm{dd}, \mathrm{Ar}-\mathrm{H}, J=16 \mathrm{~Hz}), 3.89\left(2 \mathrm{H}, \mathrm{m}, \mathrm{CH}_{2}\right), 2.71-2.58\left(2 \mathrm{H}, \mathrm{dd}, \mathrm{CH}_{2}, J\right.$ $=16 \mathrm{~Hz}) ;{ }^{13} \mathrm{C}-\mathrm{NMR}\left(100 \mathrm{MHz}, \mathrm{CDCl}_{3}\right) \delta$ 164.45-106.16 (Ar-C), $89.39(\mathrm{C}-\mathrm{O}), 30.00\left(\mathrm{CH}_{2}\right)$; ESI-MS: m/z cald.s 290.07 $[\mathrm{M})^{+}$, found-288.87 [M-1] ${ }^{+}$(Calculated for $\left.\mathrm{C}_{15} \mathrm{H}_{14} \mathrm{O}_{6}\right)$. On the basis of the above results and the available spectral literature (Shen et al., 1993 and Poon et al., 1998), compound was identified as catechin [(2R, 3S)-2-(3, 4-dihydroxyphenyl)-3, 4dihydro-2H-chromene-3, 5, 7-triol]. Catechin $\left(\mathrm{C}_{15} \mathrm{H}_{14} \mathrm{O}_{6}\right)$ is belongs to the family flavonoid, which is a kind of natural phenol belonging to the flavon-3-ols group (flavonols) (Rahman, 2013; Tomsone et al., 2012). Thus we confirm that the active compound present in $100 \%$ methanol extract of WS matured root is Catechin.

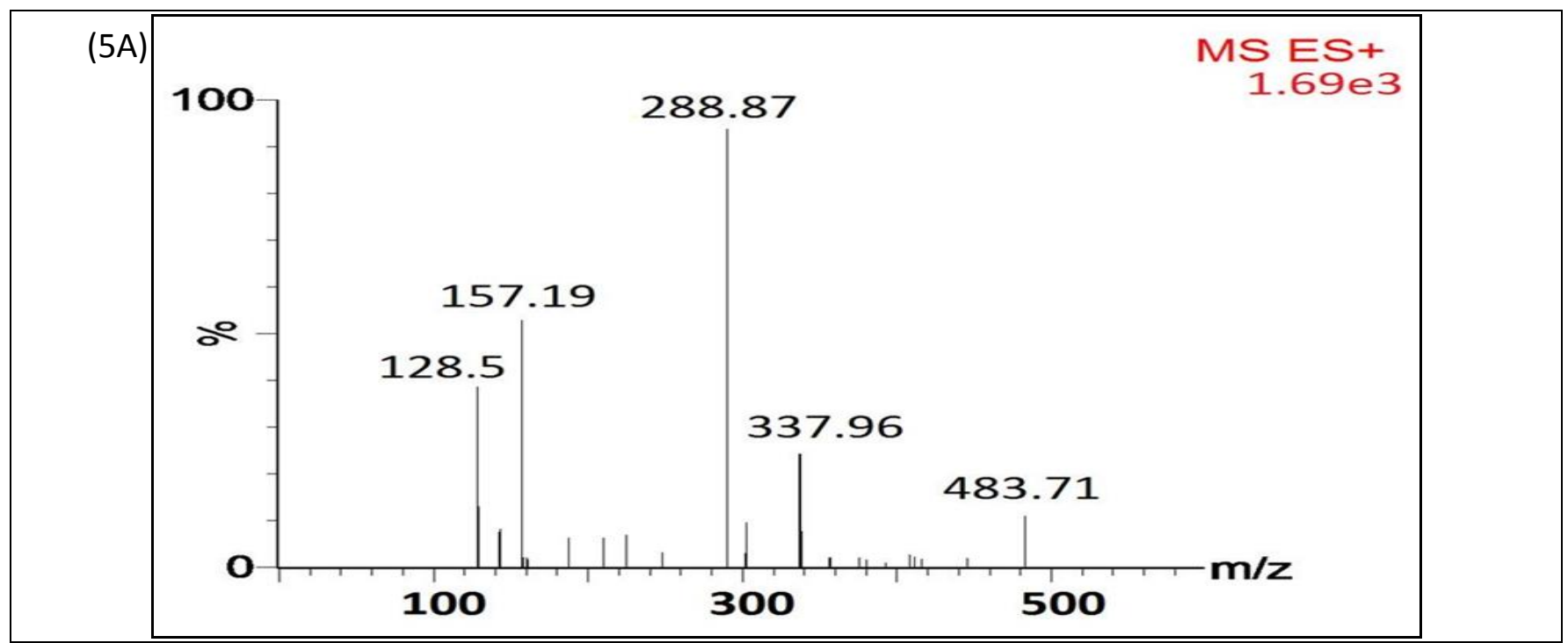




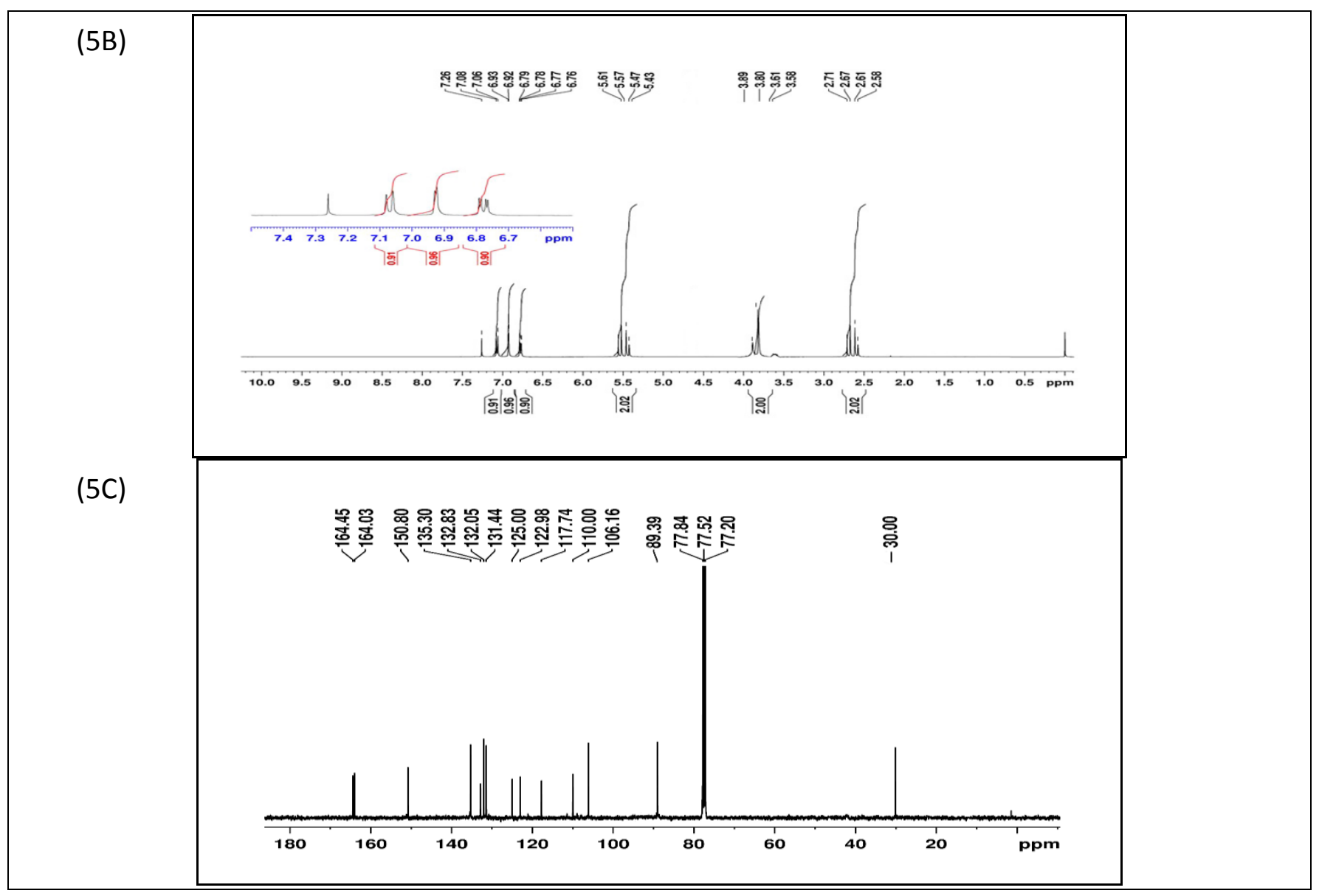

Figure 5: (A) Mass spectrum of $100 \%$ methonolic matured root extract HPLC purified 15.827 min fraction showing its mass is $288.87 \mathrm{Da}$, (B) ${ }^{1} \mathrm{H}$ NMR spectra and (C) ${ }^{13} \mathrm{C}$ NMR spectra of catechin.

Further, molecular docking of DPP-4 with catechin and other potent inhibitors revealed the potency of binding is very much similar to Withaferin A than compared to cuscohygrine, scopoletin, sitoindoside IV and tropine respectively as indicated with the docking pose (Fig. 6) and their hydrogen bonding with atomic contact energy (ACE) gliding energy scores as indicated (Table 1) along with their respective docking domain sites. Catechin from WS was found to be a active inhibitor of DPP-4 protein with binding energy $-6.60 \mathrm{kcal} / \mathrm{mol}$, in total 13 hydrogen bond interactions were found however, among them 6 interactions were strongly bound at amino acid residues of Glu 347, Met 348, Ser 349, Thr 351, Ile 375, Asn 377, Glu 378, Gly 380 and Asp 588. The -SH of Met and -OH of Ser are the main players in enhancing the binding affinity between the protein and catechin, thus leading to increased aromaticity eventually blocking the catalytic sites. However, the same residues were also seen in the standard inhibitor ligands respectively (Table 1). 

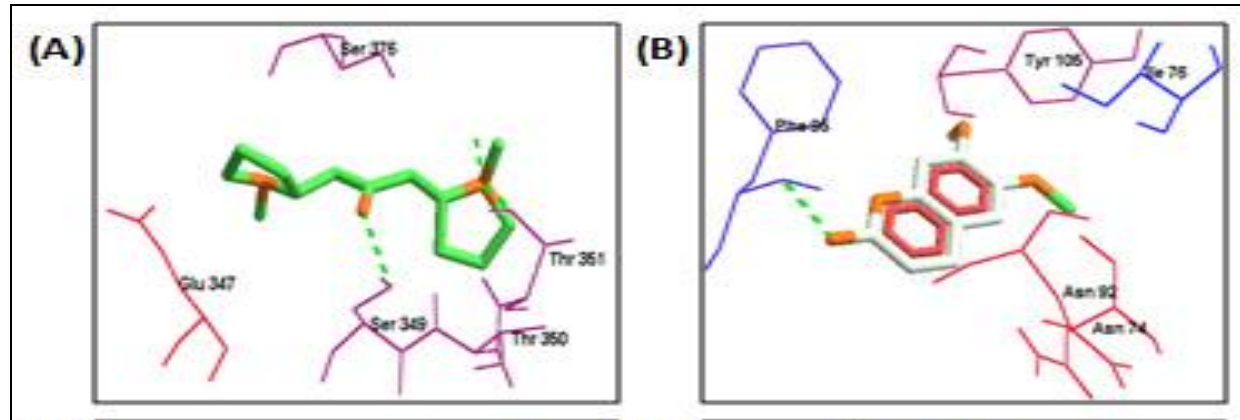

(C)

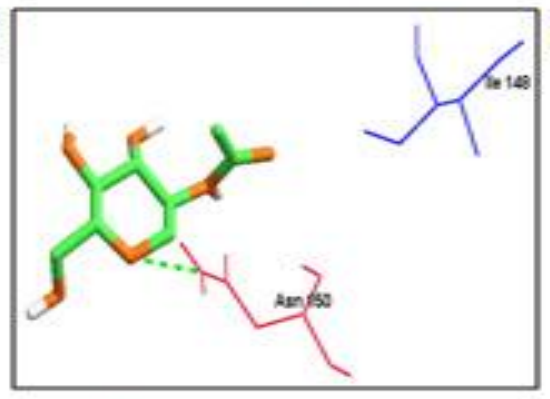

(E)

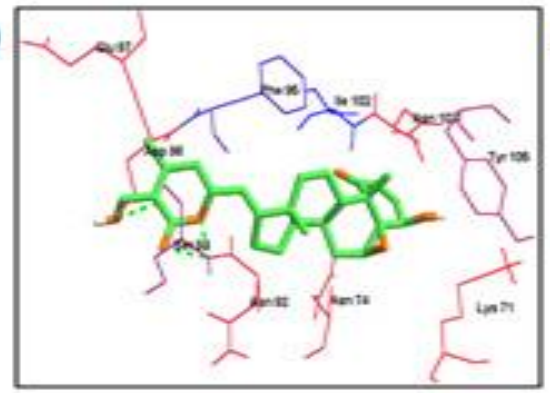

(D)

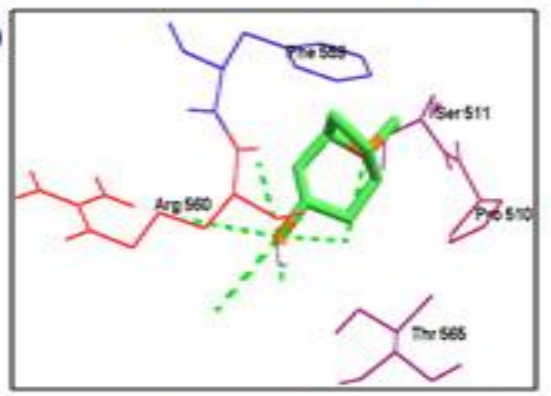

(F)

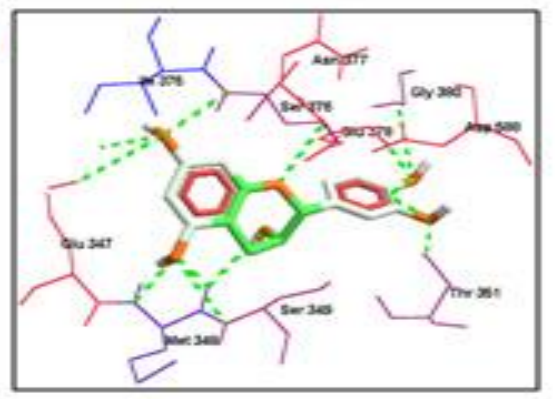

Figure 6: Structure-Activity Relationship (SAR) and binding affinity of DPP-4 enzyme with top five potent bioactive compounds of WS namely (A) Cuscohygrine, (B) Scopoletin, (C) Sitoindoside IV, (D) Ttropine, (E) Withaferin A and (F) Catechin respectively.

Table 1: Structure-Activity Relationship (SAR) and binding affinity of DPP-4 enzyme with top five potent bioactive compounds of WS namely cuscohygrine, scopoletin, sitoindoside IV, tropine, withaferin A and catechin respectively

\begin{tabular}{|c|c|c|c|c|c|c|c|}
\hline \multirow{2}{*}{$\begin{array}{l}\text { Name of the } \\
\text { biomarker }\end{array}$} & \multirow{2}{*}{$\begin{array}{l}\text { Name of the } \\
\text { compound }\end{array}$} & \multicolumn{3}{|c|}{ Details of $\mathrm{H}$-bond interaction } & \multirow{2}{*}{$\begin{array}{c}\text { Atomic } \\
\text { Contact } \\
\text { Energy } \\
\text { (ACE) } \\
\text { values }\end{array}$} & \multirow{2}{*}{$\begin{array}{l}\text { Glide Score } \\
\text { kcal/mol }\end{array}$} & \multirow{2}{*}{$\begin{array}{c}\text { Amino acid residues of } \\
\text { docked domains }\end{array}$} \\
\hline & & $\begin{array}{l}\text { No. of } \\
\text { bond }\end{array}$ & $\begin{array}{l}\text { Bond } \\
\text { energy }\end{array}$ & $\begin{array}{l}\text { Bond } \\
\text { length }\end{array}$ & & & \\
\hline & Cuscohygrine & 3 & $\begin{array}{l}-2.5 \\
-1.41 \\
2.804\end{array}$ & $\begin{array}{l}3.058 \\
3.317 \\
1.977\end{array}$ & -173.23 & -3.464 & $\begin{array}{l}\text { Glu 347, Ser 349, Thr } \\
\text { 350, Thr 351, Ser } 376\end{array}$ \\
\hline & Scopoletin & 1 & -1.307 & 3.035 & -169.24 & -3.384 & $\begin{array}{l}\text { Asn 74, Ile 76, Asn 92, } \\
\text { Phe 95, Tyr } 105\end{array}$ \\
\hline & Sitoindoside IV & 1 & -0.519 & 2.362 & -115.57 & -2.111 & Ile 148 , Asn 150 \\
\hline $\begin{array}{l}\text { DPP-4 } \\
\text { enzyme }\end{array}$ & Tropine & 7 & $\begin{array}{l}-2.5 \\
-0.564 \\
-0.284 \\
6.230 \\
-1.008 \\
2.501 \\
0.161\end{array}$ & $\begin{array}{l}3.002 \\
2.367 \\
3.543 \\
1.583 \\
3.398 \\
3.037 \\
2.281\end{array}$ & -147.19 & -2.943 & $\begin{array}{l}\text { Pro 510, Ser 511, Phe } \\
\text { 559, Arg 560, Thr } 565\end{array}$ \\
\hline
\end{tabular}




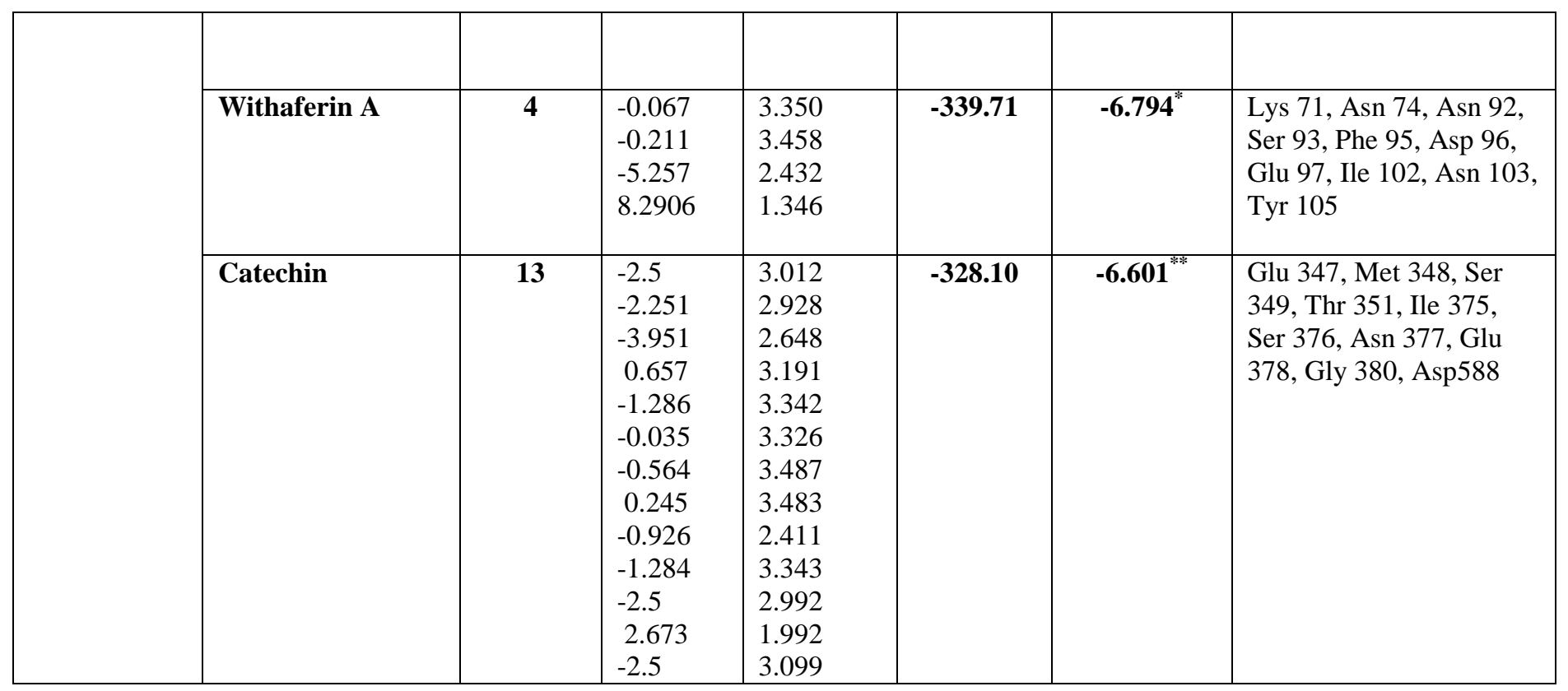

\section{Discussion}

Several studies have been carried out in the last few decades by using the various extract/chemical constituents of WS for its biological activity, mostly by using the non-standardized extract derived from the roots of wild plants. Several specific reports have evidenced the antistress, cardioprotective, antiosteoarthritis, immunomodulatory, anticancer, antitumour and antiageing (Mirjalili et al., 2009; Sharma et al., 2011; Anwer et al., 2008) of this botonical. The current study aims on the incretin based anti-diabetic approach of WS extract and its purified component by assessing the inhibition DPP-4 activity.

The $100 \%$ and $80 \%$ methanol, $1 \%$ saline solution, $0.2 \mathrm{M}$ phosphate buffer $(\mathrm{pH} 7.4)$ and $0.2 \mathrm{M}$ acetate buffer $(\mathrm{pH}$ 4.5) extracts of the root, leaves and fruit part of the young and matured plant of WS were studied for DPP-4 inhibitory activity. Among the different extract of WS, the $100 \%$ methanolic extract of matured root showed comparatively higher inhibition of DPP-4 activity with $\mathrm{IC}_{50}$ value was $8.76 \mu \mathrm{g} / \mathrm{mL}, \mathrm{Km}$ value was $97.70 \mu \mathrm{M}$ and $\mathrm{Ki}$ value was $\sim 4.157 \mathrm{e}+016 \mu \mathrm{M}$. Further, the component responsible for the inhibition of DPP-4 in 100\% methanolic extract of matured root was purified by RP-HPLC and identified as Catechin. The purified catechin was further confirmed by LCMS analysis (Fig.5A) and characterized by proton NMR spectrum of catechin (Fig.5B) was recorded using a 400-MHz spectrometer and $\mathrm{CDCl}_{3}$ as a solvent. The comprehensive data for isolated catechin are given as follows: The three doublet signals observed at $\delta 7.08-$ $6.76 \mathrm{ppm}$ was due to aromatic protons. The doublet of doublets between $\delta$ 5.61-5.43 ppm was assigned to aromatic proton. The multiplet observed at $\delta 3.89 \mathrm{ppm}$ was due to methylene protons and also a doublet of doublet observed between $\delta 2.71$ $2.58 \mathrm{ppm}$ due to methylene proton. This was further supported by ${ }^{13} \mathrm{C}$ NMR spectrum as discussed in experimental section (Fig. 5C).

Finally, In this study, catechin was identified to be very promising candidate for blocking DPP-4 protein hence to be very beneficial in the treatment of diabetes mellitus, which is evident from the results of In vitro and In silico models, together with its remarkable activity make catechin a great interest for further studies. We have shown in our previous report that, compounds from WS could act as novel inflammatory inhibitors with high selectivity and precision (Madhusudan et al., 2016). Studies are currently underway to confirm the role of this active compound(s) and to characterize the precise mechanism involved at a molecular level to trace the pathway of action. The accurately known geometries may allow us to draw some conclusions on the enzyme mechanism and suggest a possible scenario to hamper many life style disorders specifically diabetes.

Present in vitro study describes the antidiabetic activity of $100 \%$ methanolic mature root extract of WS and Catechin. Catechin is a type of natural phenol belonging to the group of flavon-3ols, a part of the chemical family of flavonoids. Catechin is one of the most important polyphenols that provide health benefits is found in WS and green tea. Modern studies have found that catechin is responsible for antioxidant activity, antimicrobial activity, anti-ageing and antidiabetic properties (Lambert and Yang, 2003; Liu et al., 2014). The potent antioxidant property of catechin reduces free radical damage to cells and prevents the oxidation of LDL, cholesterol and blood glucose level (Cooper et al., 2005; Matsui et al., 2007).

Several studies have reported that DPP-4 inhibitor drugs have been established to the therapy of type-2 diabetes mellitus. Catechin inhibition of DPP-4 enzyme activity results in increased level of bioactive GLP-1 and GIP, improved the 
glucose tolerance, HbA1c and resistant to hyperglycaemia (Joseph et al., 2009; Deacon, 2011). Nowadays incretin therapy has provided a new treatment option for patients with type 2 diabetes mellitus. The incretin therapies focus on the increasing levels of the two incretin hormones, GLP-1 and GIP. GLP-1 and GIP are hormones secreted by the enteroendocrine cells of the gut in response to the ingestion of nutrients. GLP-1 is the substrate for the enzyme DPP-4. DPP-4 is a serum protease which degrades GLP-1 into its inactive form. DPP-4 cleavage occurs at second amino acids (alanine or proline) from N-terminal. The cleavage of second amino acid (alanine) of GLP-1 by DPP-4 largely inactivates the GLP-1 (Deacon 2004). DPP-4 inhibition can be an effective approach to treat type 2 diabetes mellitus by increasing the level of active GLP-1 and also potentiates insulin secretion and suppress the glucagon secreation (Verspohl, 2009). DPP-4 inhibitor also exceeds the half-life of GLP-1 from $1 \mathrm{~min}$ to $5 \mathrm{~min}$ or some extent by inhibiting DPP-4 enzyme in the body. This GLP-1 increase in human body activates the GLP-1 receptor in pancreatic beta cell to produce insulin and lowers the glucose level in human body (Golightly et al., 2012). Same has been illustrated in Fig 7. The clinical studies of type 2 diabetes with respect to DPP-4 inhibitor were performed by so many researchers, they confirmed the above by reducing fasting blood glucose levels and HbA1c values. (Ahrén et al., 2002). Several researches have revealed that DPP-4 inhibitors as new class of anti-hyperglycemic agents. So this study demonstrates that the catechin present in WS roots could be better lead for development of new antidiabetic therapeutics.

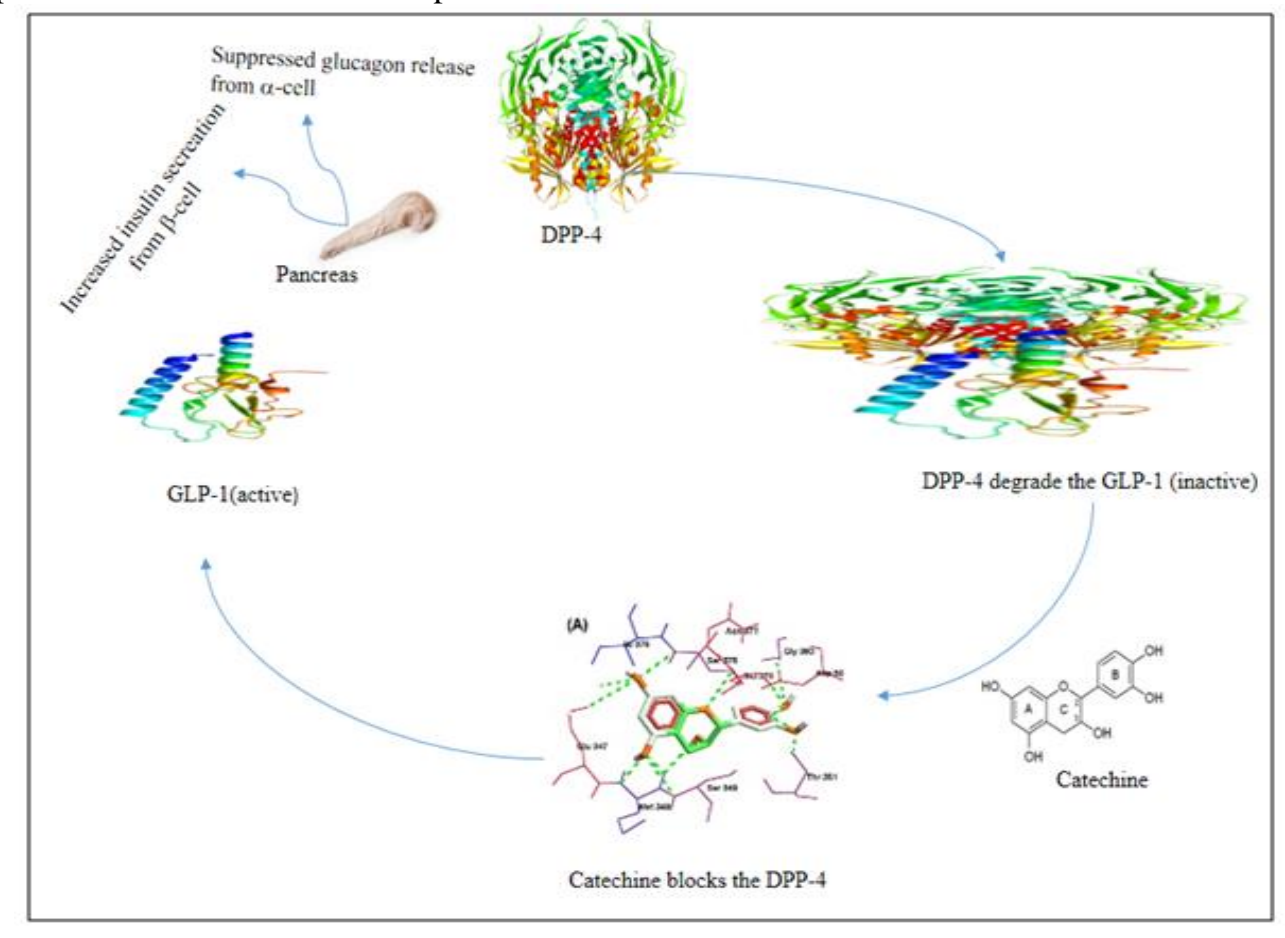

Figure 7: Schematics exhibiting the proof of concept (antidiabetics) and interaction of catechin with DPP-4 enzyme.

\section{Conclusion}

In conclusion, WS extracts has potent DPP-4 inhibitory activity. This study reinforces the ethnopharmocological observation that WS could have potent antidiabetic effects. Catechin, isolated from the plant extract may have the potential to serve as template for the development of new generation antidiabetic drug. DPP-4 inhibitor activity, enzyme kinetics, phytochemical analysis and spectral studies showed strong evidence for catechin, a flavonoid has potent DPP-4 inhibitory activity. Our plant extract acts as a DPP-4 inhibitor is likely to lower blood sugar levels by increasing the active levels of incretin hormones (GLP-1) in the body However, further work can be utilized for the in vivo and in silico method for determining the pharmacological and clinical parameters through the evaluation of antidiabetic activity of both WS plant extract and its active compound Catechin.

Acknowledgement: All authors thank PET Research Foundation, Mandya and All faculties of Department of Biochemistry and R\&D Department Bharathiar University, Coimbatore. The authors gratefully acknowledge Prof. Dr. K.S. Rangappa, Professor, Department of Chemistry, University of Mysore, Mysore and Karnataka. The authors gratefully acknowledge Prof. Dr. K.V. Prabhakara, Principal, SBRR First Grade College, Mysore, the Management, Mahajana Education Society (MES) and Research Foundation for their constant support and inspiration. FZ would like to place on record the deepest 
gratitude towards the management of Dayananda Sagar University (DSU), Bangalore and special thanks to the Dean (Dr. Sunil Moore), School of Basic and Applied Sciences, DSU, Bangalore for their constant motivation and support. Author Praveen Kumar Kempegowda specially thanks to Kalegowda Papegowda (Teacher), Kestur Koppal, Kantharajegowda Kempegowda (Teacher), Kestur Koppal, Nagarajegowda Sannaswamygowda (Superident), Malali, K R Nagar, Mysore for their constant helping to plant collection and field analysis.

Conflict of Interest: Authors have no conflict of interest.

\section{References}

1. Ahrén, B., Simonsson, E., Larsson, H., Landin-Olsson, M., Torgeirsson, H., Jansson, P. A. and Dickinson, S. (2002). Inhibition of dipeptidyl peptidase IV improves metabolic control over a 4-week study period in type 2 diabetes. Diabetes care. 25: 869-875.

2. Alam, N., Hossain, M., Khalil, M. I., Moniruzzaman, M., Sulaiman, S. A. and Gan, S. H. (2011). High catechin concentrations detected in Withania somnifera [ashwagandha) by high performance liquid chromatography analysis. BMC Complement Altern Med. 11: 1.

3. Anwer, T., Sharma, M., Pillai, K. K. and Iqbal, M. (2008). Effect of Withania somnifera on Insulin Sensitivity in Non-Insulin-Dependent Diabetes Mellitus Rats. Basic Clin Pharmacol Toxicol. 102: 498-503.

4. Baetta, R. and Corsini, A. (2011). Pharmacology of dipeptidyl peptidase-4 inhibitors. Drugs. 71: 1441-1467.

5. Barnett, A. (2006). DPP-4 inhibitors and their potential role in the management of type 2 diabetes. Int J Clin Pract. 60: 1454-1470.

6. Brown, D. X. and Evans, M. (2012). Choosing between GLP-1 receptor agonists and DPP-4 inhibitors: a pharmacological perspective. J Nutr Metab. 10: 1155.

7. Chakrabarti, R., Bhavtaran, S., Narendra, P., Varghese, N., Vanchhawng, L., Mohamed Sham Shihabudeen, H. and Thirumurgan, K. (2011). Dipeptidyl peptidase-IV inhibitory activity of Berberis aristata. J Nat Prod. 4: 158-163.

8. Cooper, R., Morre, D. J. and Morre, D. M. (2005). Medicinal benefits of green tea: part II. Review of anticancer properties. J Altern Complement Med. 11: 639-652.

9. Dalavayi, S., Kulkarni, S. M., Itikala, R. L. and Itikala, S. (2006). Determination of Withaferin-A in two Withania Species by RP-HPLC method. Indian J Pharm Sci. 68: 253.

10. Deacon, C. F. (2004). Circulation and degradation of GIP and GLP-1. Hormone and Metabolic Research. 36: 761-765.

11. Deacon, C. F. (2011). Dipeptidyl peptidase-4 inhibitors in the treatment of type 2 diabetes: a comparative review. Diabetes Obes Metab. 13: 7-18.

12. Dhananjayan, K., Sumathy, A. and Palanisamy. (2013). Dipeptidylpeptidase-4 Inhibitory Activity of Pergularia Daemia [Forsk)-An in-vitro Estimation. Asian Journal of Research in Chemistry. 6: 523.

13. Drucker, D. J. (2006). The biology of incretin hormones. Cell Metabolism, 3: 153-165.

14. Ghafoor, A. O., Qadir, H. K. and Fakhri, N. A. (2012). Analysis of phenolic compounds in extracts of Ziziphus spinachristi using RPHPLC method. J Chem Pharm Res. 4: 3158-3163.

15. Golightly, L. K., Drayna, C. C., and McDermott, M. T. (2012). Comparative clinical pharmacokinetics of dipeptidyl peptidase-4 inhibitors. Clinical pharmacokinetics. 51. 501-514.

16. Idris, I. and Donnelly, R. (2007). Dipeptidyl peptidase-IV inhibitors: a major new class of oral antidiabetic drug. Diabetes Obes Metab. 9: 153-65.

17. Joseph, A. D., Tulasi, V. K., Abhijit, R. and Bhatnagar, P. (2009). Detection of Dipeptidyl Peptidase Activity with DppivGlo ${ }^{\mathrm{TM}}$ Assay. Signal. 50: 25.

18. Khoddami, A., Wilkes, M. A. and Roberts, T. H. (2013). Techniques for analysis of plant phenolic compounds. Molecules. 18: 2328-75.

19. Kojima, K., Hama, T., Kato, T. and Nagatsu, T. (1980). Rapid chromatogrpahic purification of dipeptidyl peptidase IV in human submaxillary gland. J Chromatogr A. 189: 233.

20. Kulkarni, S. K., and Dhir, A. (2008). Withania somnifera: an Indian ginseng. Progress in neuro-psychopharmacology and biological psychiatry. 32: 1093-1105.

21. Kumar, J. S., Umesha, S., Prasad, K. S. and Niranjana, P. (2016). Detection of Quorum Sensing Molecules and Biofilm Formation in Ralstonia solanacearum. Current microbiology. 72: 297-305.

22. Lakshmi Ranganatha, V., Zameer, F., Meghashri, S., Rekha, N.D., Girish, V., Gurupadaswamy, H.D., and Khanum, S.A. (2013). Design, Synthesis, and Anticancer Properties of Novel Benzophenone-Conjugated Coumarin Analogs. Arch der Pharma. 346: 901-911.

23. Lambert, J. D. and Yang, C. S. (2003). Cancer chemopreventive activity and bioavailability of tea and tea polyphenols. Mutat Res. 523: 201-208.

24. Liu, J., Cheng, X., and Fu, L. (2012). LC-MS based assay method for DPP-IV inhibitor screening and substrate discovery. Analytical Methods. 4: 1797-1805. 
25. Liu, J., Lu, J. F., Kan, J., Wen, X. Y. and Jin, C. H. (2014). Synthesis, characterization and in vitro anti-diabetic activity of catechin grafted insulin. Int J Biol Macromol. 64: 76-83.

26. Madhusudan, M., Zameer, F., Naidu, A., Dhananjaya, B.L., and Hegdekatte, R. (2016). Contribution of Withania somnifera against Platelet Aggregation and Inflammatory Enzymes and Screening of Bioactives by Molecular Docking. Pharma Biol. 54: 1-6.

27. Mashiach, E., Schneidman-Duhovny, D., Peri, A., Shavit, Y., Nussinov, R., and Wolfson, H. J. (2010). An integrated suite of fast docking algorithms. Proteins: Structure, Function, and Bioinformatics. 78: 3197-3204.

28. Matsuda, H., Murakami, T., Kishi, A., and Yoshikawa, M. (2001). Structures of withanosides I, II, III, IV, V, VI, and VII, new withanolide glycosides, from the roots of Indian Withania somnifera Dunal. and inhibitory activity for tachyphylaxis to clonidine in isolated guinea-pig ileum. Bioorganic and medicinal chemistry. 9: 1499-1507.

29. Matsui, T., Tanaka, T., Tamura, S., Toshima, A., Tamaya, K., Miyata, Y., Tanaka, K. and Matsumoto, K. (2007). $\alpha-$ Glucosidase inhibitory profile of catechins and theaflavins. J Agric Food Chem. 55: 99-105.

30. Mirjalili, M. H., Moyano, E., Bonfill, M., Cusido, R. M. and Palazón, J. (2009). Steroidal lactones from Withania somnifera, an ancient plant for novel medicine. Molecules. 14: 2373-2393.

31. Mishra, L. C., Singh, B. B. and Dagenais, S. (2000). Scientific basis for the therapeutic use of Withania somnifera (ashwagandha): a review. Altern Med Rev. 4: 334-346.

32. Pathak, R., and Bridgeman, M. B. (2010). Dipeptidyl peptidase-4 (DPP-4) inhibitors in the management of diabetes. Pharmacy and Therapeutics. 35: 509.

33. Poon, G. K. (1998). Analysis of catechins in tea extracts by liquid chromatography-electrospray ionization mass spectrometry. Journal of chromatography A. 794: 63-74.

34. Pratley, R. E. and Salsali, A. (2007). Inhibition of DPP-4: a new therapeutic approach for the treatment of type 2 diabetes. CMRO Journal. 23: 919-931.

35. Rahman, S. M. (2013). Effect of temperature and extraction process on antioxidant activity of various leaves crude extracts of Thymus vulgaris. J Cost Life Med. 1: 130-134.

36. Rajasekar, S. and Elango, R. (2011). Estimation of alkaloid content of Ashwagandha (Withania somnifera) with HPLC methods. J Exp Sci. 2: 39.

37. Rakesh, K.S., Jagadish, S., Balaji, K.S., Zameer, F., Swaroop, T.R., Mohan, C.D., Jayarama, S., and Rangappa, K.S. (2016). 3, 5-Disubstituted isoxazole derivatives: Potential inhibitors of inflammation and cancer. Inflammation. 39: 269280 .

38. SchuÈttelkopf, A.W., and Van Aalten, D.M. (2004). PRODRG: a tool for high-throughput crystallography of proteinligand complexes. Acta Crystallogr. 60: 1355-1363.

39. Sharma, V., Sharma, S. and Pracheta, P. R. (2011). Withania somnifera: A rejuvenating ayurvedic medicinal herb for the treatment of various human ailments. Int J Pharm Tech Res. 3: 187-192.

40. Shen, C. C., Chang, Y. S. and Hott, L. K. (1993). Nuclear magnetic resonance studies of 5, 7-dihydroxyflavonoids. Phytochemistry. 34: 843-845.

41. Sinha, S. N. (2012). Screening of antioxidant and antibacterial activities of various extracts of Withania somnifera Dunal. International Journal of Pharmacology and Therapeutics. 2: 36-42.

42. Thomsen, R., and Christensen, M.H., 2006. MolDock: a new technique for high-accuracy molecular docking. J. Med. Chem., 49, 3315-3321.

43. Tiwari, R., Chakraborty, S., Saminathan, M., Dhama, K. and Singh, S. V. (2014). Ashwagandha (Withania somnifera): Role in safeguarding health, immunomodulatory effects, combating infections and therapeutic applications: A review. J Biol Sci. 14: 77.

44. Tomsone, L., Kruma, Z. and Galoburda, R. (2012). Comparison of different solvents and extraction methods for isolation of phenolic compounds from horseradish roots (Armoraciarusticana). World Acad Sci Eng Technol. 64: 903-908.

45. Trease, G. E. and Evans, W. C. (2002) Pharmacognosy. Saunders. Elsevier, Amsterdam, the Netherlands. $36: 51$.

46. Tripathy, D., and Chavez, A. O. (2010). Defects in insulin secretion and action in the pathogenesis of type 2 diabetes mellitus. Current diabetes reports. 10: 184-191.

47. Tursunova, R. N., Maslennikova, V. A., and Abubakirov, N. K. (1977). Withanolides in the vegetable kingdom. Chemistry of Natural Compounds. 13: 131-138.

48. Uddin, Q., Samiulla, L., Singh, V. K., and Jamil, S. S. (2012). Phytochemical and Pharmacological Profile of Withania somnifera Dunal: A Review. J App Pharm Sci. 2: 170-175.

49. Usman, H., Abdulrahman, F. I and Usman, A. (2009). Qualitative phytochemical screening and in vitro antimicrobial effects of methanol stem bark extract of Ficusthonningii [Moraceae). Afr J Tradit Complement Altern Med. 6: 289.

50. Verspohl, E. (2009). Novel therapeutics for type 2 diabetes: incretin hormone mimetics (glucagon-like peptide-1 receptor agonists) and dipeptidyl peptidase-4 inhibitors. Pharmacol Ther. 124: 113-138.

51. Xiao, J., Chen, D., Lin, X. X., Peng, S. F., Xiao, M. F., Huang, W. H., and Chen, Y. (2016). Screening of drug metabolizing enzymes for the ginsenoside compound $\mathrm{K}$ in vitro: an efficient anti-cancer substance originating from Panax ginseng. PloS one. 11: e0147183.

52. Yogisha, S. and Raveesha, K. A. (2010). Dipeptidyl Peptidase IV inhibitory activity of Mangifera indica. J Nat Prod. 3: 76-79. 